\title{
Managing Knowledge in Manufacturing Industry - University Innovation Projects
}

\author{
Irina-Emily Hansen ${ }^{1}$, Ola Jon Mork ${ }^{1}$, and Torgeir Welo ${ }^{2}$ \\ ${ }^{1}$ Department of Ocean Operations and Civil Engineering, Norwegian University of Science \\ and Technology, 6009 Aalesund, Norway \\ ${ }^{2}$ Department of Mechanical and Industrial Engineering, Norwegian University of Science and \\ Technology, 7491 Trondheim, Norway \\ irina-emily.hansen@ntnu.no
}

\begin{abstract}
Nowadays, manufacturing companies collaborate with universities in innovation projects to sustain or achieve competitive advantage. However, fundamental differences between the industrial and academic worlds hamper the utilization full innovation potential of such collaboration. As a countermeasure, industry stresses the need for the development of knowledge management tools that can increase the value of collaborative innovation projects. This paper covers a qualitative study of research-based innovation projects owned by manufacturing companies and partly funded by government, where the academia has the role as research provider. We seek to answer two research questions: (1) how can the strategies and objectives for collaboration to meet both partners' expectations be defined? (2) how to facilitate the projects to enhance the creation and exploiting of knowledge? The study identifies that a modified version of Nonaka's so-called five-phase model of organizational knowledge creation is applicable for the given context. Based on this, we propose a conceptual knowledge management model of university-industry collaboration in innovation projects. The proposed model provides (1) management initiatives that intensify knowledge creation and exploiting processes (2) ensures partners' commitment to collaboration along with the continuing improvement of university-industry collaborative concepts. It is proposes that the model will support knowledge managers of industry and university in conducting innovation projects more effectively and efficiently, as well as deliver even more innovation values to partners and society. The model can also assist national and federal research/innovation councils in decision-making when assessing industrial research project applications.
\end{abstract}

Keywords: Industry-University Collaboration, Knowledge Management, Innovation Project. 


\section{Introduction}

Research-based innovation projects between industry and university leverage competitiveness in the global market, while providing scientific knowledge and value for society. However, substantial differences between manufacturing companies and universities hamper collaboration, often leaving innovation potential from projects unexploited [1]. Industry stresses that the use of knowledge management tools will enable more and better quality results from innovation projects with universities [2]. This study aims to contribute to the understanding of this challenge by answering two research questions that target the main challenges in University-Industry Collaboration (UIC) projects: (1) how can strategies and objectives to meet both partners' expectations be defined? (2) how to facilitate the projects to amplify the creation and exploiting of knowledge. This study encompasses university-industry (UI) innovation projects that are owned by industry and partly funded by government, where academia has the role as 'external' research provider. The companies studied herein are characterized by mechanical production in marine and maritime businesses; including producers of propulsion systems, shipbuilders, manufactures of equipment for fish factories and similar. Within this industrial context, innovation occurs typically due to solving specific industrial problem based on tacit knowledge acquired from work experience, often through learning-by-doing, using and interacting, i.e., a so-called DUI-mode of innovation [3]. This is an important research topic since most existing UI studies are done on the scientific-technological type of innovation (STI) process in which innovation is invented by researchers for industry, and not the result of the joint activities between industry and university.

The qualitative research conducted herein identifies that Nonaka \& Takeuchi's model of organizational knowledge creation is applicable to the UI context [4]. Based on that and a somewhat modified version of their model, we propose a conceptual model of knowledge management of university-industry collaboration in innovation projects. The model aims to intensify knowledge creation and improve exploiting processes. The authors believe that knowledge managers of industry and university can use this model as a practical guideline to execute innovation projects more effectively and efficiently, thus increasing innovation impact. Moreover, the model can support national and federal research/innovation councils in decision-making when assessing industrial research applications.

The reminder of the article is organized as follows: The next section (2) introduces the theoretical background. Section 3 presents the research methodology employed. The research findings are summarized in Section 4 and followed by a discussion in Section 5. Section 6 gives conclusions and further work.

\section{Theoretical Background}

The acknowledged organizational knowledge creation model is introduced by Nonaka $\&$ Takeuchi [4]. It consists of five phases: sharing tacit knowledge, creating the concept, justifying the concept, building of an architype and cross-leveling knowledge. 
The project team starts with sharing tacit knowledge. People share knowledge they acquired through personal experiences in the specific knowledge fields. For instance, the technology integrator can provide insights into feasibility of the technology integration in factories. Based on the ability to share tacit knowledge team members create a concept of a new product, process or service. The created concepts must be justified against criteria identified by knowledge goals and the needs of society. Justifying the concept often involves experts outside of the project group. Ones the concept is justified, it must be tested by an archetype. The last step, cross-leveling of knowledge, implies the sharing of knowledge derived from the project with the rest of the organization. Cross-leveling triggers new cycle of knowledge creation forming a spiral process accentuating that organizational knowledge creation is a continuous and process.

\section{Methodology and Background for Study}

The study covers the so-called 'user-driven research-based innovation' type of project. 'User' is an industrial company, which typically submits an application to the Research Council for financial support [5]. The Research Council (RCN) of Norway provides financial support for collaboration between industrial companies and research organizations to promote innovation and sustainable value creation through research-based innovation. RCN stimulates industry to innovate and mitigates the risk of innovation by covering around $40 \%$ of the cost of such projects. Typically, most cash funding for external academic research in such projects is funded by RCN. The company contributes in-kind (hours and equipment), some cash funding and acts as a contract partner with RCN for such projects and is therefore responsible for the project and its budget.

The context for this study are the manufacturing companies and a university campus located on the west coast of Norway. The size of the companies and their R\&D capabilities vary significantly. There are some large companies with plans for research many years ahead, they are the ones that comprise their own basic research. However, the majority of companies are smaller with significantly shorter research horizons. This work focuses on two research questions: (1) how to define goals for collaboration to meet the expectations of industry and university, and (2) how to facilitate projects to amplify knowledge creation and exploiting. Fifteen individual semi-structured interviews were conducted. The respondents were six academic project managers, six industrial projects managers, two academic $\mathrm{PhD}$ candidates, and one $\mathrm{PhD}$ employed by one of the companies. Furthermore, the workshop with fourteen PhDs and two senior researchers was arranged to collect input to the study. The first and second authors of this paper facilitated the workshop. Moreover, seven observations of an ongoing project, including formal and informal meetings combined with nine semi-structured interviews were conducted as a part of this study.

\section{4. $\quad$ Findings}

The collected data was used to create a new knowledge-management model of UI collaboration in innovation. The proposed model reflects the necessity of several aspects 
to support the knowledge creation process in the UI context-ones that are not considered by Nonaka \& Takeuchi's model: (1) commitment of resources, (2) managerial initiatives that support not only the creation of knowledge, but also its exploitation.

Commitment of dedicated resources to the project is one of the major tasks in managing UI projects [2]. Therefore, the proposed model is organized at three interdependent levels; i.e., each organization's strategic level, UI collaborative strategic level, and UI project level as shown in Fig. 1. Integration of the project level into UI collaborative level and integration of the latter into top-management level reflect the necessity of topmanagement to support and prioritize the projects by allocating them sufficient resources, even in competition with operational needs and daily business.

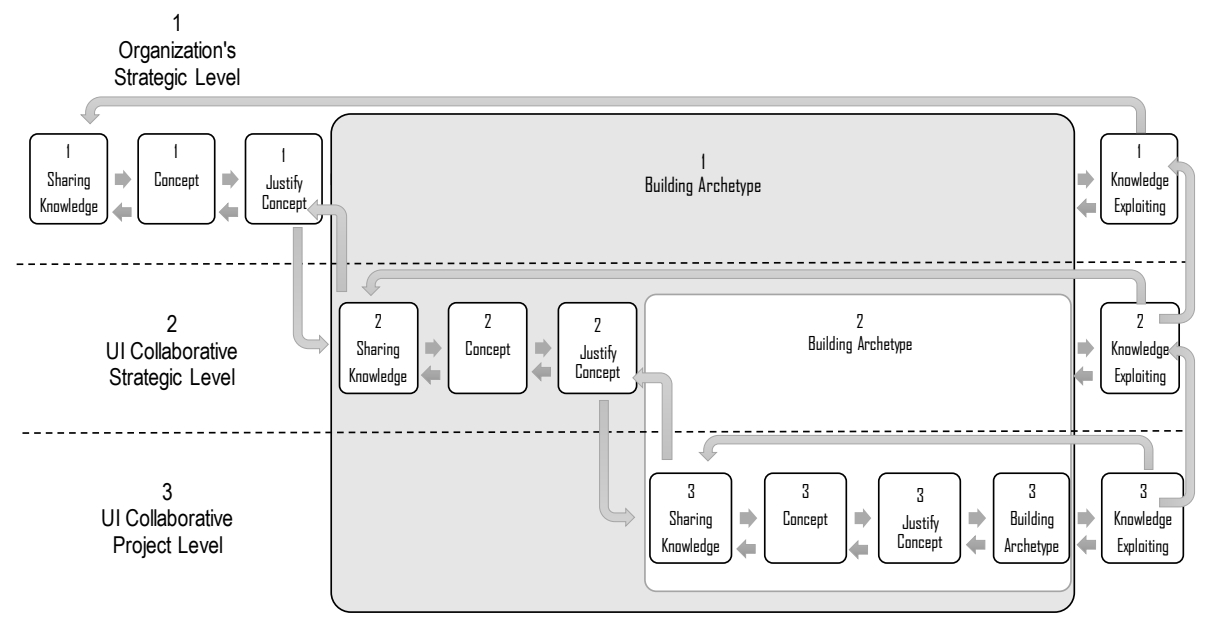

Fig. 1 Conceptual model of knowledge management of UI innovation projects

Exploiting knowledge in innovation projects is a major concern. Even when the projects generate new ideas, they are not always used in ongoing project. To accentuate the importance of this aspect, the last phase in UI collaboration model is formulated as 'knowledge exploiting'. Table 1 presents conceptual solutions that collectively support knowledge exploiting by answering the research questions on how to identify collaborative goals and facilitate knowledge processes. The collaborative concepts emerged from the data analysis. The scrutiny of the data from interviews and observations led to categorizing data into collaborative concepts on three levels: each organization's strategic level, UI strategic level, and UI project level.

The model incorporates continued improvement of collaborative concepts. Fig. 1 shows that each organization's grand concept for collaboration in innovation is verified at the UI collaborative level. Here, the step 'building architype' on level one triggers the knowledge creation process at UI collaborative strategic level two. Both concepts go through the test on project level: the knowledge-creation process on project level three evaluates the quality of the concepts from the levels above. Thus, the project functions as an archetype of level one and level two. For instance, a constant shortage of resources from university and industry in the project would imply a revision of the collaborative concepts at all levels. 
Table 1. University-industry innovation projects: collaborative concepts

\begin{tabular}{|c|c|c|}
\hline Concept level & $\begin{array}{l}\text { How to define } \\
\text { collaborative goals }\end{array}$ & How to facilitate innovation \\
\hline $\begin{array}{l}\text { Organization's } \\
\text { strategic level }\end{array}$ & $\begin{array}{l}\text { Knowledge vision } \\
\text { and strategy with } \\
\text { national and re- } \\
\text { gional directions } \\
\text { for innovation }\end{array}$ & $\begin{array}{l}\text { Dedicate and allocate resources for collaboration: } \\
\text { - PhD programs } \\
\text { - Industrial management and senior researchers } \\
\text { support PhDs } \\
\text { - Interdisciplinary collaboration }\end{array}$ \\
\hline $\begin{array}{l}\text { UI collaborative } \\
\text { strategic level }\end{array}$ & $\begin{array}{l}\text { Building } \\
\text { knowledge plat- } \\
\text { form: long-term } \\
\text { collaborative strat- } \\
\text { egy }\end{array}$ & $\begin{array}{l}\text { - Clarification of partners' expectations } \\
\text { - Strategic UI project group: members are in- } \\
\text { volved in many UI projects } \\
\text { - Absorptive capacity of involved: industrial and } \\
\text { academic background }\end{array}$ \\
\hline UI project level & $\begin{array}{l}\text { Project objectives } \\
\text { are aligned with UI } \\
\text { collaborative strat- } \\
\text { egy }\end{array}$ & $\begin{array}{l}\text { - Clarification of partners' expectations } \\
\text { - Anchoring the projects at top-management } \\
\text { - Industry should navigate the project } \\
\text { - Involve internal and external stakeholders } \\
\text { - Provide common language } \\
\text { - Create a momentum: keep enthusiasm }\end{array}$ \\
\hline
\end{tabular}

\section{Discussion}

The study shows that the organizational five-step model of the knowledge-creation process introduced by Nonaka \& Takeuchi can be applied to knowledge management in UI collaboration with some modifications. Modifications are consistent with the answers to the research questions: how to define collaborative goals and how to facilitate knowledge-creation and exploiting. The model contributes to UI collaboration by (1) providing collaborative concepts that intensify knowledge creation and exploiting processes, (2) ensuring the commitment of partners in collaboration and providing for the continuing improvement of UI collaborative concepts. In the following, each of these contributions will be discussed separately.

\subsection{Collaborative Concepts for Knowledge Creation and Exploitation}

The concept at each level of collaboration contains specific initiatives that provide creating and application of new knowledge thereby ensuring success of UI innovation projects. The contribution to each phase of the knowledge creation process are considered individually.

The Sharing tacit knowledge phase includes sharing experiences to enable sharing mental models. The involvement of people with backgrounds from academia and in- 
dustry, such as senior researchers and highly educated industrial employees, helps partners to rapidly relate to each other. Integrating academic $\mathrm{PhD}$ candidates in a company's operational environment generates common experience with industry, making it easier to share tacit knowledge. University and industry knowledge strategies crystallize the multiplicity of shared mental models in one direction [4]. The managerial initiative at project level creating a momentum by delivering a value in the beginning of the project quickly, generates positive collaborative experience and accelerates sharing of tacit knowledge. For instance, researchers can use their methodological tools to solve a few small industrial problems at the very beginning of the project.

Concept creation is about how the partners are going to collaborate in innovation. Table 1 depicts the concepts guidelines how to define the goals for collaboration in innovation and the initiatives to achieve these goals. Dedication of the resources for innovation project is the core of the Concept creation. In practice, partners should assign which knowledge contributors are required for the project and the adequate quantity of time they will use on the project. For instance, the project requires that one engineer uses $40 \%$ of their time, two days a week, to design the prototype and participate in prototype building. The mechanic and electrician each will use $20 \%$ of their time to work on prototype. The same concerns the university. The project manager on behalf of the university and the researchers from the required knowledge fields, for example, expert in automation and software developer will be assigned time they are required to use on the project. Dedication of resources is crucial for project success. Otherwise, daily routines will take over and UI innovation project will be given less priority. Concept creation implies also initiatives that support 'shared language'. Avoiding academic terminology, use of industrial language, sketches, drawings, and mockups are the means that provide mutual understanding. The model emphasizes the role of the strategic UI project group that collaborates over time on many technological projects. Accumulating collaborative experience helps to execute the project more effectively.

Clarification of expectations in strategies and objectives supports Concept justification. This study suggests that the top management in university and industry has the main responsibility to incorporate justification criteria in organizational knowledge vision and strategy, which must be consistent with national and regional plans in research and development. The collaborative UI unit should establish a set of sub criteria in the form of a UI collaborative strategy for a long-term partnership, which is in line with the knowledge strategies of organizations. Consequently, the project objectives present the set of sub criteria that coincide with the justification criteria at the above levels. The research questions should be defined in line with the industrial needs and have some room for flexibility due to uncertainty in innovation projects. Involving stakeholders, people from different departments in companies and universities, end users of future innovative solutions, is vital for creation and justification of the concepts.

Building archetypes is a necessary part of creating a new process or new product. Rapid prototyping and frequent interactions with users are a prerogative for success. Additionally, a prototype is a great communication tool for people from different backgrounds. Using it frequently will improve communication between industry and academia and increase the quality of the knowledge creation processes. 
Cross-leveling knowledge depends on university and industry committing resources to undertaking projects and implementing the results. The university should provide enough time for the researchers to be able to integrate new knowledge into educational programs and develop it further through other projects with industry. To ensure implementation of research findings in industry, one should actively involve company's customers and/or operational users of new knowledge in the project. That will ensure that project will meet industrial requirements and make the company commit the resources to execute the project and implement the results. Moreover, the engagement of operational users in the project will give them ownership of new knowledge, creating willingness to use it. The study also emphasizes that integration of technology experts in the project ensures the feasibility of applying project results.

\subsection{Commitment and Continuous Improvement of Collaborative Concepts}

Fig. 1 illustrates the embeddedness of the project and strategic UI collaborative levels in the main knowledge creation process of each organization. This means that creating and exploiting knowledge at the project level need support from a collaborative UI strategic unit and the decision-makers at the top-level of each organization. Therefore, the grand concept at each organization's strategic level emphasizes the necessity of topmanagement commitment to collaboration. Without this, the basis for initiating a new project is lacking. The model's dynamic provides continuous improvement of collaborative concepts. The collaborative concepts at three levels function interdependently. Universities and industrial companies define their own grand concept for collaboration with others in innovation. The grand concept must support the concepts for collaboration at the levels below: the common UI collaborative strategy level and the UI project level. Modifications on each level of the collaboration trigger the optimization processes on the other levels. Continuous improvement makes the model dynamic.

\subsection{Verification of the proposed Knowledge Management Model}

The proposed model is newly developed. The first assessment of the theoretical model was made in the workshop with the participants from one accomplished UI innovation project. The project leader from the university, the $\mathrm{PhD}$ candidate and industrial $\mathrm{PhD}$ candidate who, during the project had to take over the role of the project manager on behalf of the company, evaluated the collaborative concepts. The criteria for evaluation was the degree of impact form the concepts' substances on the projects: low, middle and high. The participants assessed the concepts individually. They also discussed the formulation and content of the statements.

The participants saw the model's potential to help university and industry deliver more innovation. They asserted that the model could also be a tool for setting up new projects for further exploration and exploitation of knowledge derived from the project. The workshop results help the researchers to develop a more practical version of the model for implementation. Conversion of the theoretical model into practical guidelines will make it easier for knowledge managers of university and industry to apply and validate the model. The plan is to use focus groups to test if practical guidelines give 
meaning and are suitable for practical application. The focus groups will involve experienced project managers from university, industry and representatives from RCN. The true contribution of this work can only be evaluated through the comparison before and after applying the proposed approach to the real innovation project. In this connection, it is worth noting that this is a typically three-years long project and it would take long time to get the final results. Moreover, one should develop the criteria for comparing the innovation impact of the projects with and without employing of the model. As many projects as possible is the best for validation. However, one should be aware of the amount of work and necessity to ensure the quality of validation.

\section{Conclusion}

This research contributes to knowledge management theory by adapting the organizational knowledge creation theory of Nonaka \& Takeuchi to the context of UI collaboration projects. In practice the model has a potential to support university and industry in conducting innovation projects more effectively and efficiently. The model provides the collaborative concepts on the three levels: strategic organizational, UI strategic collaborative level and UI project level. The concepts are the knowledge management initiatives that support creation and application of knowledge in innovation project. They encompass the specific recommendations of how to define collaborative knowledge goals and the activities to achieve them. The model emphasizes the importance of continued knowledge exploitation that triggers constant improvement of the collaborative concepts on all levels. The future research shall validate the effect of application of the model to the projects. Although the study covers mechanical engineering companies in marine and maritime sectors on the west coast of Norway, the issues between university and industry are common in other industries and alike for any private-public collaboration.

\section{References}

1. Perkmann, M., Tartari, V., McKelvey, M., Autio, E., Broström, A., D’Este, P., Fini, R., Geuna, A., Grimaldi, R., Hughes, A.: Academic engagement and commercialisation: A review of the literature on university-industry relations. Res. Policy. 42, 423-442 (2013)

2. Hansen, I.-E., Mork, O.J., Welo, T.: Towards a framework for managing knowledge integration in university-industry collaboration projects, (2018)

3. Lundvall, B.-Å.: Interactive Learning, Social Capital and Economic Performance. Adv. Knowl. Knowl. Econ. 63-74 (2006)

4. Nonaka, I.: A dynamic theory of organizational knowledge creation. Organ. Sci. 1, 14-37 (1994). doi:10.1287/orsc.5.1.14

5. Research Council of Norway, https://www.forskningsradet.no/prognettbia/Programme_description/1226993636103 